\title{
KAUFMANN, Carolina. Textos escolares, dictaduras y después: miradas desde Argentina, Alemania, Brasil, España e Italia. Buenos Aires: Prometeo Libros, 2012. 304 p.
}

\author{
Wilian Carlos Cipriani Barom*
}

Carolina Kaufmann é doutora em Educação pela Universidade de Valladolid, Espanha, e atualmente é professora titular de História Social da Educação na Universidade Nacional de Entre Ríos, Argentina.Com vasta publicação na área, vem traçando um caminho de estudos que inter-relaciona memória, ditadura militar e educação.A presente obra, publicada pela editora PrometeoLibros, no ano de 2012, coroa a trajetória da autora em um projeto ambicioso que busca dar conta de cinco contextos diferentes: Argentina, Alemanha, Brasil, Espanha e Itália. Nesta intenção, convidou autores especialistas que expuseram suas análises ao longo dos oito capítulos da obra, que totalizam 304 páginas. São análises pontuais, mas que, quando tomadas em conjunto, enriquecem os estudos que entrecruzam ditadura militar e educação.

Para o caso específico da obra, os manuais didáticos foram tomados como documentos, em que os autores se debruçaram e lançaram suas análises. Os quatro primeiros capítulos se referem ao contexto da ditadura e pós-ditadura militar argentina. O quinto discute a realidade brasileira, seguido das análises de Espanha, Alemanha e Itália. Para o caso italiano, não se refere particularmente ao governo italiano, mas, sim,às representações da América Latina, em especial da ditadura militar argentina, nos manuais de língua estrangeira italianos.Isso atribui ao todo da obra maior ênfase no estudo do contexto argentino. De modo geral, é um estudo empírico da sociedade em contexto de transição democrática pós-ditadura militar, num cruzamento entre movimentos sociais, poder estatal, empresas editoriais e representações.

O primeiro capítulo ("Manuais de educación primaria en la Argentina (1984-1993)", escrito pela professora doutora Graciela M. Carbone, da Universidade Federal de Buenos Aires) pode ser descrito como um grande esforço para o desvelamento da complexidade do real, das tensões e contrastes que estiveram presentes no período logo após o fim da ditadura militar na Argentina. Múltiplas vozes se hierarquizaram numa relação truculenta, em disputas por espaço nos cenários políticos, e que se relacionaram direta ou indiretamente à produção dos

*Doutorando do Programa de Pós-Graduação em Educação da Universidade Estadual de Ponta Grossa. Professor da Rede Estadual de Ensino do Estado do Paraná. E-mail: <wilianbarom@yahoo.com.br> 
manuais didáticos do período. É objetivo da autora, a partir do estudo de caso da realidade municipal de Buenos Aires, apontar os diversos discursos que estiveram presentes nessa primeira etapa do governo democrático e que colaboraram para a gestação das políticas públicas educacionais.

Nesta intenção, Carbone busca arquitetar os discursos presentes na sociedade em cinco dimensões que se articulam: os que estiveram presentes nas Assembleias do Conselho Federal de Educação; na atuação da Comissão Assessora Honorária do Congresso Pedagógico Nacional; nos Foros, Seminários e Conselhos; nas iniciativas práticas da Gestão Nacional; e nas entrevistas de alunos e diretores de escolas de nível primário. Uma tentativa de aproximação entre o local e o nacional, entre as intenções discursivas dos foros populares e o que prescreveram as leis quando efetivadas, e entre a normativa legal e o "currículo real" que se evidenciou em ambiente escolar na segunda metade da década de 1980. Para a realização desse trabalho, a autora recorreu às leis criadas no período que versaram sobre ensino e a outros estudos acadêmicos, que foram dispostos lado a lado, na intenção de detalhar e caracterizar este período transitório.

As conclusões da autora se espalham por todo o texto, conforme vai avançando e relacionando as dimensões. De modo geral, indicamos aqui sua ênfase na coexistência de heranças ditatoriais e vozes democráticas, que se refletem nos livros didáticos, nas aulas dos professores, nos discursos escolares e nos projetos curriculares. Apesar dos esforços realizados no enfrentamento da "atomização" do ensino, sua submissão às esferas municipais, o que se evidenciou na prática foi uma tentativa de unificação nacional com ainda fortes reminiscências de uma ideologia autoritária. Inicialmente, a ideia de uma unidade na diversidade não foi contemplada satisfatoriamente nos documentos criados, algo que a autora aponta diantedo insucesso das incipientes iniciativas democráticas do Conselho Federal de Educação. A gestão nacional manteve práticas incoerentes com o avançar do exercício democrático, como criar documentos fundantes para os âmbitos regionais, baseados ainda nos objetivos e conteúdos mínimos do período ditatorial.

No âmbito escolar, os livros didáticos mantiveram suas representações positivistas da realidade, enfatizando a cronologia, os fatos isolados, o progresso, a obediência, a família hierárquica, um saber "atemporal", "aespacial" e "associal". Nos discursos dos alunos, prevaleceu uma compreensão harmônica da sociedade, ausente de incoerências ou conflitos, gestada no processo de "civilização" do indígena. Os alunos também apontaram a necessidade da submissão à Pátria e à Constituição, por ser a vontade da maioria, para se manter a ordem e garantir o respeito ao próximo. Carbone indicou tambéma ausência, nos discursos dos alunos, de expressões que remetessem ao caráter representativo do governo, seu processo de eleição, a ideia de participação popular, ou expressões que remetessem à coletividade. Os professores e diretores, em seus discursos, 
manifestaram consciência da necessidade de superação das permanências ditatoriais, porém afirmaram encontrar dificuldades em como conduzir esse processo de mudança.

No segundo capítulo do livro ("1984-1993: Una miscelánea de propuestas editoriales en un territorio curricular atomizado"), Carbone dá continuidade à discussão anterior e envereda para uma análise interna aos livros didáticos. Sua amostragem refere-se aos períodos dos governos de Raúl Alfonsín (1984-1989) e Carlos Menem (1989-1993). De acordo com a autora, as editoras postergaram suas reformas, provocando um possível atraso intencional nas adaptações internas, nas renovações. Enquanto a sociedade se renovava, os livros envelheciam. No entanto, a autora aponta a existência de editoras que estiveram na vanguarda desse processo de renovação/inovação, e busca analisar suas obras ${ }^{1}$ que tiveram maior circulação.

De início, as inovações vieram da intenção de substituir a forma "enciclopédica” de escrita e de exposição do conteúdo. Em meio aos múltiplos discursos presentes na sociedade, um arco de iniciativas apresentou-se, mesclando tendências tecnicistas e críticas. Para descrever e contrastar essas mudanças que se evidenciaram, Carbone mais bem conceitua a forma de ensino tida como "enciclopédica" que se encontra em momento de superação. Por esta definição, entende a forma textual de organizar os conteúdos tendo como características a cronologia, a linearidade, a trama descritiva, o formalismo na formação do cidadão e do Estado, a ideologia em defesa da religião, o culto ao processo colonizador e a representação excludente dos povos indígenas.

Ao analisar os manuais didáticos, aponta que as inovações não se instalaram de modo uniforme, e que muitas mantiveram características da forma enciclopédica. Contudo, de maneira mais ou menos ampla, questões significativas foram inseridas, de certa forma refletindo os discursos mais democráticos da sociedade. Carbone descreve e analisa obra por obra, na intenção de identificar quais seriam as inovações de cada coleção, que aqui sintetizamos em: inserção crescente do olhar temático, análise local, reelaboração da representação dos imigrantes, indígenas e povos colonizadores, análise dos problemas e população local, desenvolvimento das noções de ruptura e continuidade e a ideia da História como uma construção, com documentos e perspectivas. Ainda se verificam detalhes técnicos, como maior utilização de imagens, ilustrações, planos, perspectivas, cores, texturas, diálogos e relatos.

Ao término de seu texto, Carbone sugere a necessidade de aprofundamentos, novas pesquisas, que avancem no estudo das possíveis tensões entre

\footnotetext{
${ }^{1}$ A exemplo de Aula Taller, Ciencias Sociales, Manual Del Alumno, Estudios Sociales, Manual Estrada Bonaerense, Doce +1 e Manual Santillana.
} 
as prescrições curriculares municipais e nacionais e os currículos que se manifestaram via manuais didáticos nesse período de recuperação democrática na Argentina. Deve-se ainda investigara tensão entre as proposições dos manuais didáticos e o currículo que efetivamente ocorreu em ambiente escolar nessa década, o "currículo real".

O terceiro capítulo ("La Dictadura em los textos de civismo argentinos (1983-1986)", escrito pela organizadora do livro, professora doutora Carolina Kaufmann) é uma análise de como o acontecimento da ditadura militar argentina reflete-se nos textos de educação cívica, em especial do autor Emílio Fermin Mignone, educador e defensor dos direitos humanos.

A partir dos estudos de Kaufmann sobre outros manuais de civismo, Mignone merece destaque por ser um autor com características peculiares, intencionalmente ideológico, propondo-secriar uma obra que colabore na consolidação da democracia argentina. Seus manuais já se destacam pala capa, com imagens que problematizam o voto, a eleição de autoridades, a livre expressão, a irmandade latino-americana e a justiça. Outra característica é a utilização de fotografias recentes como documentos históricos, a exemplo das mães em protesto pelo desaparecimento de seus filhos e do julgamento dos militares realizado em 1985. Em dois volumes da coleção "Educación Cívica" (1986), $1^{\circ}$ e $2^{\circ}$ anos, encontra-se um total de 50imagens, com funções variadas: motivação, exercício epistemológico, informação ou explicação. A linguagem textual possui valores claros: expressões como "poder sem ética", "mentiram", "arruinou a economia, a educação e a cultura do país", "hoje padecemos por essa falta de ética" são utilizadas na intenção de intervir na interpretação do aluno. O tema ditadura militar aparece em vários momentos do livro, diluindo-se em diversas discussões, não se restringindo a um capítulo ou parágrafo.

No quesito "como fazer", como criar um civismo crítico, a obra inova em atividades que superam as tradicionais "perguntas e respostas". Outras formas de se relacionar com o conteúdo são apresentadas como exercícios de opinião, análises de imagens, dinâmicas de grupo, que buscam fomentar a capacidade reflexiva, crítica e criativa dos alunos. Kaufmann conclui o texto apontando a importância da obra de Mignone para a proposição de um civismo com "informações úteis", que articule a História aos elementos da realidade sociopolítica do momento presente, que relacione local, regional e nacional, de forma a propiciar aos alunos elementos de uma autonomia responsável, um papel mais ativo na sociedade, na defesa da democracia e da manutenção permanente dos direitos civis.

O quarto capítulo ("La última ditadura militar argentina en los manuales de Educación General Básica”, escrito pelos professoresGonzalo de Aménzola, Carlos Dicroce e Maria C. Garriga, da Universidade Nacional de La Plata) busca 
analisar como, nas décadas posteriores ao término da ditadura militar, inseriu-se nos manuais didáticos a história recente da Argentina. Otexto busca ilustrar como se deu a mudança paradigmática de educar por grandes feitos de heróis para educar a partir de ações errôneas e vergonhosas de ditadores.

A análise dos livros de $9^{\circ}$ ano, das editoras Kapelusz, Santillana e Estrada - década de 1990 e início de 2000 -, é entrecruzada com informações contextuais significativas, a exemplo das políticas de anistia de Carlos Menem aos militares condenados, dos movimentos sociais e de contramemória que buscaram justiça e condenação no final da década de 1990 e das medidas do presidente Kirchner em favor das políticas de memória, reabrindo os julgamentos aos condenados.

A história recente enuncia-se nas prescrições curriculares em 1993 e permanece na reforma educacional de 2006. De acordo com os autores, cada vez mais os manuais estão sendo escritos coletivamente, diminuindo-se a ideia de um único redator para cada manual, sendo ainda consultados especialistas antes de seu término, apoiando-se cada vez mais em bibliografias atualizadas. Contudo, não escapam dos interesses do mercado, possuindo uma escrita destinada aos interesses das classes médias consumidoras, escolas privadas, que acaba por atribuir características conservadoras na forma da escrita.

Comparando os manuais, os autores apontam um formato de narrar a ditadura militar que vem se repetindo: primeiro, o terrorismo do Estado;depois, o plano econômico ditatorial, que gerou crises e dívidas; e, por fim, a Guerra das Malvinas, como irresponsabilidade do governo militar e fator que colaborou na decadência do regime, e privatizações. Outras conclusões ainda são apontadas: o manual da editora Estrada é o que destacou mais abertamente a defesa dos direitos humanos, refletindo a preocupação contemporânea do movimento "Nunca Mais", trazendo testemunhos como documentos e formas metodológicas diferenciadas de abordar e problematizar; o manual Santillana apresentou um modelo descritivo baseado em perguntas e respostas; e o manual Kapelusz enquadrou-se como intermediário entre os anteriores. Ao término do texto, os autores apontam que, para escapar dos interesses unicamente do mercado, o governo argentino tem se inspirado nos modelos brasileiro e mexicano de seleção dos manuais didáticos. Assinala também a necessidade de a crítica analisar os movimentos de esquerda, evitando-se uma santificação de todos os acontecimentos e uma desconsideração apurada dos crimes.

O quinto capítulo ("Brasil: financiación, ideología y resistencia. De la dictadura a la renovación editorial”, escrito pela professora Kazumi Munakata, da Pontifícia Universidade Católica de São Paulo) colabora com o anterior, na medida em que expõe, de modo curto e preciso,como se consolidou o modelo editorial brasileiro de manuais didáticos. Aponta que,no Brasil, os manuais 
didáticos foram ao mesmo tempo difusores da ideologia da ditadura e um campo de resistência ao regime militar.

O surgimento das casas editoriais está ligado ao financiamento do governo militar e à parceria com o governo norte-americano via acordo MEC-Usaid. Milhões de dólares foram destinados ao desenvolvimento das áreas de distribuição, impressão, encadernação, fabricação do papel, ilustração e formação de professores. No final da década de 1960, estima-se que mais de 6 milhões de livros foram impressos e distribuídos a 3 milhões de alunos. Esse convênio com a política norte-americana não avança para a década de 1970, mas realiza um forte impulso e um atrelamento entre os interesses do Estado e das casas editoriais. Um segundo momento, de consolidação, é a criação do Grupo Executivo das Indústrias de Papel e Artes Gráficas (1966), que negociou com o governo a liberação da importação de máquinas gráficas, atualizando o cenário industrial gráfico brasileiro.

Como nos capítulos anteriores, analisando também manuais que circularam na época da ditadura, Munakata destaca que os principais transmissores de ideologias militares eram os de Educação Moral e Cívica e História, que justificavam em seus textos o golpe militar como "revolução" e combate ao "perigo comunista", com um estilo ufanista de escrita. Adentrando na década de 1980, manuais, como o de Renato Mocellin, já tratavam o acontecimento do regime militar como um "golpe", além da criação da disciplina Organização Social e Política do Brasil (OSPB) e da publicação da obra Introdução à Política Brasileira, de Frei Betto, que denota a incipiente aproximação das editoras com a vertente da Teologia da Libertação da Igreja Católica e de ideias socialistas.

O sexto capítulo ("La imagen de América Latina en los textos escolares del bachillerato franquista (1939-1975) - Una herramienta política de la dictadura”, escrito pela professora doutora Clara R. Guerrero, também da Universidade de Valladolid, Espanha) tem como objeto as representações da América Latina nos manuais didáticos do período franquista. A autora trabalha os conceitos de "inconsciente coletivo" e "memória coletiva" visando identificar as imagens mentais, presentes na sociedade, sobre a América Latina, que, de certa forma, são refletidas nos manuais, assim como também seu inverso. Como filtro de análise, a autora busca as representações referentes aos seguintes temas: descobrimentos, conquista, colonização e independência.

Guerrero organiza o governo de Francisco Franco em cinco períodos, com base nas leis que versaram sobre educação: 1938, 1953, 1957, 1967 e 1970. Essa periodização abarca desde o Estado espanhol em sua forma extremamente nacionalista, católico, de combate ao comunismo, em contexto de guerra, até o período de sua burocratização, voltada ao desenvolvimento técnico, de 
alinhamento com as políticas de desenvolvimento econômico e o surgimento significativo das empresas privadas. A autora também reconstrói, via legislação, o processo de ampliação da escola pública, para então analisar nos manuais as representações da América Latina.

De modo sintético, nos primeiros períodos, descobrimento, conquista e colonização estão atrelados a um processo missionário de realização da nação espanhola. Conforme vontade divina, o Estado espanhol realiza-se no "civilizar", em transmitir a cristandade ao próximo. Haveria um destino a ser seguido, valores universais, num estudo de apenas personagens que tiveram importância excepcional no acontecer histórico, na ligação de conquistas com os documentos oficiais papais. O processo de independência é visto a partir de explicações externas, que não remetem ao controle metropolitano. Posteriormente, os conteúdos migraram para uma abordagem mais pragmática, centrada na explicação da estrutura político-social da Espanha, do processo de colonização, dos direitos, deveres e aspirações das comunidades ibero-americanas. A ideologia da formação do espírito nacional baseada na hispanidad, com valores absolutos e religiosos, passa a ser substituída por uma formação política, social e econômica, pelo autor definida como o período da "negação das ideologias".

Também se referindo ao estudo de representações, o sétimo capítulo ("De Sevilla a Jerusalén. El juego de lasilla o sobre las representaciones de judíos y gitanos en los manuales de texto alemanes (RFA y RDA 1949-2004)", escrito por Liliana Ruth Feierstein, pós-doutoranda na Universidade de Konstanz, Alemanha) busca realizar uma análise de como judeus e ciganos foram retratados nos manuais alemães de História, de 1949 a 2004. Destoando um pouco dos capítulos anteriores, por não se relacionar diretamente ao contexto das ditaduras militares, acaba servindo no interior da obra como um estudo sobre a cultura que se mantém após um governo militar autoritário. Haveria, assim, uma cultura que é fabricada a partir das legislações e ações concretas do regime, e que permanece após sua queda.

A partir de um vasto estudo de 120 manuais e 40 materiais complementares, a autora aponta que essas minorias continuam a ser retratadas como "estranhas", "outros", numa relação binária "nós/eles". Em poucos manuais houve espaços para as vozes dos representados. As duas Alemanhas construíram narrativas nacionais para o Holocausto, mas não conseguiram superar a ideia binária. A autora apresenta,então, a hipótese de que o povo alemão acabou interiorizando o trato com os judeus e manifesta essa cultura excludente inconscientemente.

Os manuais não discutem o processo de diáspora e a cultura que mantém a identidade judaica, normalizando a questão territorial de Israel.Para o caso cigano, o silêncio é ainda maior, referindo-se à busca por raízes indianas num 
processo contínuo de regresso à terra de origem, que não é a Alemanha. Não abordam os múltiplos judaísmos que se desenvolveram, os regionalismos, ou as relações entre os povos e o meio em que estão desenvolvidos. Atribuem suas identidades unicamente ao viés territorial atrelado a Israel, o que acaba por excluí-los constantemente da Alemanha. Além dos manuais permanecerem, indiretamente, com a representação que atribui culpa às vítimas, não demonstrando corretamente as resistências que ocorreram, continuam tratando os judeus como "judeus" - nãopelo nome - quandosão ilustrados nos exemplos, coisificando-os constantemente. Conclui a autora que a cultura nazista mantém-se forte, velada, num reafirmar da cultura cristã dos autores pela representação estereotipada de judeus e ciganos.

O último capítulo ("Latinoamérica en los manuales de español como segunda lengua utilizados en Italia", escrito pelas professoras doutoras Carolina Kaufmann, Maria Fernanda Santarrone e Roxana C. Mauri Nicastro) retoma o engate com os iniciais, porém permanece no estudo das representações. É objetivo do texto analisar os manuais das últimas décadas de língua espanhola, produzidos na Espanha e na Itália,tentando identificar as representações da América Latina. Essas representações são também articuladas com entrevistas de professores. É um texto que diverge dos anteriores por possuir outra forma de escrita, uma análise que parte do campo linguístico, e não da História, muito embora Kaufmann seja uma das autoras. A abordagem dos manuais levanta elementos novos, como o cuidado com as elaborações das frases, os conceitos utilizados, as interpretações possíveis de uma mesma sentença, os interditos, mas que não deixa de cruzar essas informações com cultura, políticas e poder.

O traço eurocêntrico é a marca dos manuais analisados. Uma abordagem monocultural da América Latina, que se apresenta por estereótipos atrelados ao comércio turístico, numa dinâmica de oposição entre a representação do espanhol e do latino-americano. Este último tem sua imagem representada como o "quase" espanhol, carecendo dos elementos que caracterizam os peninsulares. O europeu espanhol é retratado como o normal, o racional, o civilizado e o desenvolvido, em oposição ao indígena latino-americano, que é apresentado como o anormal, o irracional, o bárbaro e o subdesenvolvido. Essa oposição se dá porimagens contrastadas entre o moderno e o subdesenvolvido, chegando até a comparação estética das fisionomias, elegendo, inconscientemente e com base numa abordagem racial, o estereótipo "ocidental" de beleza, branco e europeu como ideal.

Os manuais também não consideram as divergências linguísticas do espanhol nos países da América Latina. Não abordam todos os países do continente, elegendo sempre Chile, Argentina, Peru, Cuba, Venezuela, Colômbia e Uruguai 
para ilustrar, diferenciando-os unicamente por suas comidas, paisagens e clima e unificando-os na história e sociedade.

No que se refere às ditaduras militares, em especial a argentina, simplificam e generalizam em afirmações como "extrema direita", "extrema esquerda", "combate aos comunistas", sem considerar os contextos particulares, os movimentos sociais, as contradições ou diferenças entre países. Em geral, quando os manuais se referem à Espanha, tratam de temas da atualidade; e, quando se referem aos países latino-americanos, apresentam uma visão étnico-folclórica. 